\title{
DE LA ILUSTRACIÓN A LA UTOPÍA
}

\author{
José Santos Puerto \\ UNIVERSIDAD DE LA LAGUNA
}

\section{RESUMEN}

El autor se queja en este artículo de que las disputas del último tercio del siglo XX en torno a las figuras de Mayans y Feijoo propicia la minusvaloración de otros ilustrados contemporáneos, sobre todo de los del bando feijooniano, al tiempo que favorece la multiplicación de muchos personajes con capa de ilustrados que acaso no merecen título de tal. Por eso el autor cree que es conveniente clarificar qué elementos podrían servir para caracterizar a esos que podemos llamar ilustrados. Y por último, tomando a Martín Sarmiento como modelo, intenta explicar cómo, por qué y en qué momento el ilustrado pudo dejar de serlo para pasarse al otro bando, en el caso de Sarmiento al del inconformismo y la utopía.

Palabras Clave: Ilustración española. Utopía. Martín Sarmiento.

\section{ABSTRACT}

In this article the author complains that the disputes about Mayans and Feijoo in the last third of the 20th Century favors the undervaluation of other contemporary erudite researchers, mainly the ones in favor of Feijoo, at the same time it favors the increase of people with a hint of erudition but perhaps not deserving it. That is why the author thinks that it is advisable to clarify which elements could serve to characterize those who could be named as erudite. And finally, taking Martín Sarmiento as a model, he tries to explain how, why and in which moment the erudite researcher could stop being so and joins the opposite belief, in the case of Sarmiento being nonconformist and utopian.

Key Words: Spanish Enlightenment. Utopia. Martin Sarmiento.

\section{LAS HISTORIOGRAFÍAS BIENPENSANTES}

Yo me atrevería a decir, parafraseando a Feijoo cuando hablaba de la crítica en una de sus Cartas Eruditas, que desdichado es hoy el pueblo de las Españas que no puede presumir de ser la cuna de algunas docenas de ilustrados. ¡Lo que va de unos tiempos a otros! Cincuenta años atrás todavía resonaban las palabras de Ortega y Gasset: nosotros no hemos tenido, porque nos 
lo saltamos, el gran siglo XVIII educador; un siglo insustituible que en otras partes había sido tiempo de mentalidades abiertas, de gran confianza, optimismo y fe en el destino del hombre.

Cierto es que hace cincuenta años los tiempos empezaron a cambiar, sobre todo cuando Jean Sarrailh puso en escena a las minorías selectas que en la segunda mitad del siglo de las Luces intentaron modelar una España nueva. Y casi de manera simultánea otros investigadores españoles descubrieron que ni aquellos heterodoxos eran tan herejes y afrancesados como nos los había pintado Menéndez Pelayo, ni el siglo XVIII había sido el más perverso y amotinado contra Dios, como sentenciaba el montañés.

Lo dijo José Antonio Maravall de manera contundente: “creo que la generación de mis maestros sufrió un error de óptica al apreciar el siglo XVIII en España, y aunque algunos no dejaron de estimar algunas de sus aportaciones, se equivocaron en general al medir el espesor de lo que su sedimentación había dejado en la sociedad española"1. Y también lo explicó en varias ocasiones el profesor Caso González, director que fue durante muchos años del Centro de Estudios del Siglo XVIII de Oviedo. En 1952 estaba a punto de comenzar a redactar su tesis de doctorado, que versaba sobre Jovellanos. Al parecer tenía ya todo el material preparado cuando se encontró con algunas dificultades de última hora, que creyó poder solventar acudiendo al Archivo Histórico Nacional. Conviene darle la palabra:

"Comencé a pedir legajos. Y empecé a descubrir un mundo tan distinto de aquel en que yo creía, que cada día significaba algún importante descubrimiento. Entonces me lancé como un loco sobre periódicos como El Censor y sobre otra literatura non sancta, y me siguió apareciendo algo tan nuevo, que era un siglo XVIII que nada tenía que ver con el que yo había aprendido. En definitiva, había sido víctima de la historiografía bienpensante. Lógicamente la tesis, terminada cuatro años después, no tuvo nada que ver con la que yo tenía programada en 1952. Supongo que por los mismos años debieron ocurrir a otros experiencias semejantes a la mía”2.

Con la expresión víctima de la historiografía bienpensante el profesor Caso hacía referencia al olvido, el desprecio y la condena que padecieron los pensadores de nuestro siglo XVIII, como consecuencia de las disputas que se produjeron en torno a ellos en la España decimonónica. No sé yo si en las disputas del último tercio del siglo Xx en torno a Mayans-Feijoo acaso se ha vuelto a conformar otra historiografía bienpensante, por seguir la expresión de Caso. Por eso creo que puede ser conveniente clarificar de nuevo qué entendemos por ilustrado. Y explicar también por qué y en qué momento el ilustrado pudo dejar de serlo, ya porque se pasó a la camarilla del déspota de turno, o porque prefirió el otro bando, el del inconformismo y la utopía. Eso es lo que pretendo abordar en este artículo, que retoma algunas ideas ya desarrolladas en otros estudios.

\section{ES REGLA SEGURA QUE SE DEBE PREFERIR LA RAZÓN A LA AUTORIDAD}

La máxima kantiana del Sapere aude, ten valor para servirte de tu propia razón, o el imperativo ;Atreveos a pensar por vos mismo! que el conde Medroso recibió de lord Boldmind, aquel oficial inglés que contribuyó a dar por un tiempo un Rey a España y que en el reposo del

1 Maravall, J. A.: Estudios de la Historia del Pensamiento español (s. XVIII), compilación de Ma C. Iglesias, Madrid, Mondadori, 1991, pág. 246. La cita corresponde a un trabajo de 1979, "Espíritu burgués y principio de interés personal en la Ilustración española", publicado en Hispanic Review.

2 Caso, J. M.: "Recuperar la Ilustración", en La Ilustración española, Cuadernos de Historia 16, n 44, Madrid, 1985, pág. 8. También Caso J.M.: "Fortunas y adversidades de un investigador dieciochista", en Actas del Seminario de Ilustración Aragonesa, Zaragoza, 1987, págs. 9-16. 
guerrero herido quiere liberar las almas condenadas a galeras ${ }^{3}$, no son meros arbitrios pedantes que vienen bien citar en nuestros libros y artículos cuando hablamos de Ilustración. Se trata, por el contrario, del método que debemos seguir en los estudios acerca de ese período. El método que nos acercará en alguna medida a aquella definición que hizo Feijoo de sí mismo: "ciudadano libre de la República Literaria, ni esclavo de Aristóteles ni aliado de sus enemigos, escucharé siempre con preferencia a toda autoridad privada, lo que me dictaren la experiencia y la razón"4; método que nos permitirá hacer lo que hicieron muchos hombres de aquel tiempo: criticar, disentir, destruir prejuicios, dudar para intentar responder por nosotros mismos iserá cierto?

Quiero decir que los que estudiamos cuestiones relacionadas con la Ilustración no podemos renunciar a la posibilidad de ilustrarnos y de mejorar nuestra capacidad de crítica, teniendo en cuenta aquella otra sentencia de Feijoo: "es regla segura que se debe preferir la razón a la autoridad"5. Claro que al seguir esa máxima podemos encontrarnos con grandes dificultades: los escollos, bajos, arrecifes, corrientes, peñascos ocultos que se deben considerar si la pluma no se acomoda a todos, habría dicho Martín Sarmiento ${ }^{6}$. Pero si hablamos de Ilustración no podemos eludir el compromiso.

El de 2002 fue un año importante para el conocimiento de Fr. Martín Sarmiento, pues entonces le homenajeó toda Galicia, dedicando al benedictino su día más grande, el Día das Letras Galegas. Pues bien, en ese mismo año salió a la luz el libro Felipe $V$ y los Españoles, de Ricardo García Cárcel, catedrático de Historia Moderna en la Universidad Autónoma de Barcelona. La obra, que había obtenido ese mismo año 2002 el Premio "Así fue. La Historia rescatada", es muy interesante por múltiples razones que no es aquí momento de exponer con detalle.

Quiero subrayar un par de afirmaciones del profesor García Cárcel, con las que estoy totalmente de acuerdo: "Hoy la visión clásica de Sarrailh y Herr, retrasando la ilustración hasta Carlos III, ha quedado desautorizada por múltiples trabajos"; y más adelante "a mi juicio, se ha contrapuesto de modo demasiado simple al intelectual oficial Feijoo y al independiente Mayans". Si consultamos el índice onomástico del libro de García Cárcel, descubrimos que el nombre de Martín Sarmiento sólo aparece en una ocasión. Y al acudir a la página señalada, encontramos que esto es lo único que se dice del benedictino: "Las obras de Cornide, Sarmiento, Somoza de Monsorín... traslucen una enorme agresividad contra los <explotadores > catalanes" 7 . Extraña circunstancia la de hablar del tiempo de Felipe V sin acordarse de quien era el personaje principal de las Letras Gallegas el año de 2002.

No debe considerarse esto como reprobación del estudio de García Cárcel. Lo que pretendo señalar es que el profesor de la Universidad de Barcelona no cae en la cuenta de que muchos de los trabajos que han desautorizado la visión de Sarrailh y de Herr no han podido sustraerse al segundo sesgo que él criticaba. Es decir, el de contraponer a Mayans y a Feijoo para delimitar quién de los dos es más precursor ilustrado a cambio de olvidar a los otros españoles de la primera mitad del siglo de la Ilustración. Ese ha sido acaso el gran acierto de Mestre para realzar la figura de Mayans.

Me explico. Nadie dudará hoy de la importancia que en las últimas tres décadas han tenido los estudios de Antonio Mestre para una mejor comprensión de la Ilustración española en general, y para

\footnotetext{
Voltaire: Diccionario Filosófico, voz "libertad de pensamiento". Aquí cito por la edición castellana de Akal, Madrid, 1985.

4 Feijoo: Teatro Crítico Universal, Tomo VII, Disc. 13 Lo que sobra y falta en la física, XI, § 35. Las obras de Feijoo son asequibles en internet: http://www.filosofia.org/feijoo.htm

Feijoo: Cartas Eruditas, II, carta 18, De la Crítica, § 29.

6 Sarmiento: Cartas al Duque de Medinasidonia, edición de J. Santos, Ponferrada, Instituto de Estudios Bercianos, 1995, págs. 106-107.

7 García Cárcel, R.: Felipe V y los españoles. Una visión periférica del problema de España, Barcelona, Plaza y Janés, 2002. Las citas en las páginas 143,156 y 287 respectivamente.
} 
la figura de Gregorio Mayans en particular. Un Mayans prácticamente ausente en la España Ilustrada de Sarrailh pero que de la mano de Mestre -y antes de la pluma de V. Peset y después de François Lopez y José Antonio Maravall, entre otros- ha encontrado su lugar en la historia moderna de España.

En los primeros tiempos Mestre tuvo que enfrentarse con la perturbadora imagen que nos presentaba a España como un desierto cultural y científico antes de 1726, fecha en que comenzó a ver la luz la obra de Feijoo. Nacida ya en el propio siglo XVIII español ${ }^{8}$, esa imagen había vuelto a proyectarse de nuevo con fuerza en los años treinta del siglo XX con los estudios dedicados al benedictino por Marañón y Delpy, y luego en el libro de Sarrailh, ya que Marañón y Delpy fueron norte y guía para el encuentro del rector de la Universidad de París con Feijoo, "le grand ancêtre auquel il faut toujours revenir"'.

Así que los trabajos iniciales de Mestre no consistieron sólo en estudiar las aportaciones culturales e históricas de Mayans, situándole en el contexto político y cultural de su tiempo, y en publicar sus cartas y obras, sino también en buscar otros antepasados y otros antecedentes científicos y culturales en los que poder encuadrar una nueva forma de entender los inicios de la ilustración española que diera cabida protagonista a Mayans. El propósito, sacar a la luz ese movimiento que hoy conocemos como el tiempo de los novatores, en buena medida lo habían iniciado ya Quiroz, Ceñal y López Piñero, entre otros, y luego fue bien sintetizado por François Lopez en su estudio sobre Forner ${ }^{10}$.

No era suficiente, sin embargo, saber que Feijoo no estaba tan solo ni había sido el único ni el primero preocupado por encender las luces de las Españas. Para que Mayans cobrara verdadero protagonismo en las luces españolas del siglo XVIII era necesario que ahora, a finales del XX, apareciera rivalizando con Feijoo, y a ser posible oscureciéndole. Y esa era una de las siguientes tareas principales a emprender. En alguna medida se trataba de minusvalorar la figura del de Oviedo hurgando repetidamente en aquellas de sus insuficiencias que pudieran contraponerse con las suficiencias de Mayans.

No digo yo que Mestre carezca de razón al afirmar que "nuestro benedictino no usa la razón -y menos de modo implacable - al estudiar los orígenes de la cristiandad hispana y concretamente las tradiciones jacobeas", pero el contraste no me parece muy válido, aunque haya sido efectivo por tantas veces repetido: "el mérito de aceptar la crítica histórica hasta las últimas consecuencias pertenece a otra generación y a otro personaje, con quien manifestó el benedictino sus divergencias en repetidas ocasiones"11. Y digo que es poco válido el contraste, aunque Mestre lo haya repetido hasta la saciedad, porque Feijoo no era historiador, por más que escribiera algunos enjundiosos ensayos sobre la historia y que levantara gran polvareda su intervención en la polémica Ferreras-Berganza.

Quién sí hizo papel de historiador crítico, en sintonía con los benedictinos de San Mauro, fue su discípulo y amigo Sarmiento, como sin duda supo Mestre al menos desde que conoció la tesis de Michel Dubuis ${ }^{12}$. Sorprende por eso que Sarmiento casi siempre haya aparecido en la obra de Mestre vinculado solamente al affaire de la España Primitiva como protagonista negativo en contraste con Mayans. Y digo casi siempre porque en este asunto ha dado recientemente un completo giro a su posición.

En efecto, en 1970 Mestre juzgaba la actitud de Sarmiento en relación con la censura de la España Primitiva de esta manera: "Sarmiento, el otro censor que hubiera podido apoyar el parecer del valenciano, calla alegando que bastaba el juicio de don Gregorio". En 1976 asegura que

\footnotetext{
Sarrailh, J.: L'Espagne Éclairée de la Seconde Moitié du XVIII siècle, Paris, 1954, pág. 8.

Lopez, F.: Juan P. Forner et la crise de la conscience espagnole au XVIII siècle, Bordeaux, 1976.

Mestre, A.: Mayans y la España de la Ilustración, Madrid, 1990, pág. 161.

Dubuis, M.: L'Espagne et Saint-Maur. La Congregation de Valladolid dans le mouvement erudit entre 1670 et 1790.

Tesis doctoral, Universidad de París, 1982.
} 
el benedictino tuvo intención de aprobar la España Primitiva, aunque finalmente declinó el encargo para no desacreditarse, idea que mantenía más de una década después, con motivo de su participación en el Coloquio Internacional sobre Carlos III y su siglo. Un lustro después, aunque ya admitía la importancia de Sarmiento como historiador crítico, mantenía los mismos criterios en cuanto a la España Primitiva: "Salvo la huida ante la encargada censura de la España Primitiva, su postura ante los estudios históricos siempre fue decidida y valiente"13.

El cambio se produce en el año 2000, primero de manera tímida en un artículo publicado en Cuadernos Dieciochistas: "el benedictino presentó una censura negativa, pero sin atacar a la Real Academia de la Historia. Aunque no había visto el manuscrito en que se basaba la España Primitiva, se opone a que salga su nombre como quien la aprobaba, al tiempo que recomendaba la censura a otra persona". Y en 2004 la cuestión aparece zanjada: "El benedictino fue duro en la crítica del libro y rechazó los planteamientos de los falsos cronicones, pero aconsejaba el juicio de otro colega que hubiera visto directamente el manuscrito original" ${ }^{14}$. Mestre no ha aclarado -al menos que yo sepa- qué razones le llevaron a ese cambio radical. Sí sé que citar nuestras fuentes no es ningún acto de generosidad, sino un ejercicio de honestidad intelectual y de respeto por nuestros maestros y discípulos. Y creo que Feijoo tenía razón en aquella máxima que cité al principio: "es regla segura que se debe preferir la razón a la autoridad".

Y creo, así mismo, que en ese proceso de contraposición entre Mayans y Feijoo, buscando cuál de los dos merece más el título de ilustrado, hemos olvidado algo que recordaron no hace mucho Saavedra y Sobrado: "Hoy ya nadie defiende las ideas de Marañón a propósito de la aparición de una especie de páramo aislado y bárbaro; pero aunque Feijoo no esté solo, su influencia no debe empequeñecerse, pues su labor de divulgación fue realmente novedosa y el eco de sus escritos no sólo queda reflejado en la rápida venta de los volúmenes del Teatro Crítico y de las Cartas Eruditas, sino en los ataques de los que fue objeto por escolásticos y eruditos"15.

También creo que al abrigo de la disputa Feijoo-Mayans se han vuelto a perder en el camino a muchos ilustrados, sobre todo a los del bando feijooniano, a la vez que, olvidada la preferencia de la razón frente a la autoridad, han aparecido una retahíla de personajes que en la segunda mitad del siglo XX tomaron ropas de ilustrados para llenar con sus nombres las plazas, las calles, las revistas y las bibliotecas municipales.

Entiéndase: no digo yo que estén desacertados los que quieren quitar de las calles de España los nombres de los golpistas, cambiándolos por los mejores hijos de sus pueblos. Lo que no me parece bien es tener que inventar etiqueta de ilustrado a tal cual personaje, sólo porque vivió o murió en tiempos de los primeros Borbones. Y lo que más me aturde es que quienes así proceden recurrentemente citan a Jean Sarrailh, pero olvidan que según el rector de la Universidad de París los ilustrados eran sólo uno pocos: "ils ne formaient qu'une petite troupe intrépide, qui ne redoutait pas les coups et qui, lorsqu'elle ne pouvait livrer bataille au grand jour, savait reculer et déjouer les embuscades"16.

13 Mestre, A.: Historia, Fueros y actitudes políticas: Mayans y la historiografía del siglo XVIII, Valencia, Ayuntamiento de Oliva, 1970, pág. 391; Despotismo e ilustración en España, Barcelona 1976, págs. 120-121; "La historiografía española del siglo XVIII", en Actas del Coloquio Internacional sobre Carlos III y su siglo, Madrid, 1990, tomo I, pág. 43; "El P. Martín Sarmiento", en G. Carnero (coord), Historia de la Literatura española. Siglo XVIII, Madrid, Espasa Calpe, 1995, pág. 96

14 Mestre, A.: "Monarca, instituciones e individuos en los orígenes de la Ilustración”, Cuadernos dieciochistas, 2000, págs. 19-37. El artículo se recogió después en Apología y Crítica de España en el siglo XVIII, Madrid, Marcial Pons, 2003, págs. 95-118. La cita en pág. 112; Mestre, A. y Pérez, P.: "La cultura en el siglo XVIII español”, en Luis Gil et al., Historia de España Moderna. La cultura española en la Edad Moderna, Madrid, Itsmo, 2004, pág. 413.

15 Saavedra, P. y Sobrado, H.: El siglo de las Luces. Cultura y vida cotidiana, Madrid, Síntesis, 2004, pág. 24

16 Sarrailh, J.: L'Espagne Éclairée de la Seconde Moitié du XVIII siècle, citada, pág. 710. 


\section{EL ILUSTRADO ESPAÑOL, UN INTENTO DE CARACTERIZACIÓN}

¿Eran los ilustrados tan escasos como decía Sarrailh, o por el contrario son tantos como hoy pueblan las historias locales y autonómicas? ¿Cómo saber cuánto tiene de ilustrado este o el otro personaje? A mí me parece que inicialmente debemos partir de esta idea: el ilustrado español es un hombre de progreso preocupado por la desdichada existencia de sus compatriotas, casi todos campesinos sin recursos y explotados en una tierra que no les pertenece. Tierra escasamente productiva, con excesivas cargas y tributos, que está en manos de unos pocos propietarios y de "infinitos intermediarios, sacaliñas, sacamantas, sacatrapos y sacabocados que quieren ser reyes"17.

La mayoría -Feijoo, Sarmiento, Campomanes, Olavide, Meléndez Valdés, Cabarrús, Jovellanos y tantos otros- se duelen continuamente de la grave situación: "El descuido de España lloro -decía Feijoo-, porque el descuido de España me duele". Se duele no sólo del atraso, la ignorancia y la credulidad, sino principalmente del hambre, la sed, la enfermedad y la desesperación de la población rural y campesina: "No hay gente más hambrienta -decía también Feijoo-, ni más desabrigada, que los labradores. Cuatro trapos cubren sus carnes; o mejor diré, que, por las muchas roturas, que tienen, las descubren (...) Su alimento es un poco de pan negro (...) pero todo en tan escasa cantidad, que hay quienes apenas una vez en la vida se levantan saciados de la mesa"18.

La situación de explotación del campesinado español la sintetizó también Jovellanos: "No ha bastado agravar su condición, haciendo recaer sobre ella los pechos y servicios de que se dispensaba al clero, a la nobleza y a otras clases menos respetables; no ha bastado hacer caer sobre ella el efecto de todas las franquicias concedidas a la industria, y de todas las prohibiciones decretadas en favor del comercio (...) Las quintas, los bagajes, los alojamientos (...) y todas las cargas concejiles agobian al infeliz agricultor, mientras que con mano generosa se exime de ellas a otras clases y profesiones" 19 .

El ilustrado cree que hay que fomentar la agricultura --primer apoyo de la fuerza y el esplendor de las naciones, decía Jovellanos en el citado Expediente de Ley Agraria-- introduciendo nuevas técnicas, perfeccionando las labores, mejorando los riegos, repoblando y poniendo en producción la tierra baldía, y orientando ese fenómeno económico que después se ha venido a denominar, con Richard Herr, "el auge de la tierra y el ansia de poseerla" 20 . Algunos proponen una limitación de la extensión de tierras en manos muertas, a la vez que un reparto de los baldíos y propios de los pueblos para que se desmonten y se cultiven, otros piden la creación de nuevas poblaciones. Se elaboraron informes y expedientes de desamortización, pero casi todo quedó en proyecto, prueba sin duda de las limitaciones de aquel reformismo ilustrado casi siempre incapaz de cuestionar la propiedad privada y el orden social y agrario establecido.

Hay también que mejorar las vías de comunicación. Por eso Sarmiento redactó en 1757 uno de los proyectos más coherentes de su siglo para construir una red radial de caminos desde Madrid a todos los puntos de España, y allí era contundente: "ha llegado para España el siglo de hacer caminos" 21 . Se ha dicho que era un proyecto quimérico, "la utopía matemática del siglo"

\footnotetext{
Sarmiento: Obra de 660 pliegos, Biblioteca Nacional, Colección Dávila, XIV, Ms. 20390, §684.

Feijoo: Teatro Crítico, vol. VIII, discurso 12, "Honra y Provecho de la Agricultura". Las referencias en $\S$ VII, 25 y $\$ \mathrm{X}, 41$.

Jovellanos: Informe sobre la Ley Agraria, BAE, L, pág. 121.

Herr, R.: España y la Revolución del s. XVIII, Madrid, 1971, cap. 4.

1 "Creo que ha llegado para España el siglo de hacer caminos. Ya era tiempo, a la verdad, después de tan repetidas quejas y de la notoria necesidad que había en España de unos buenos caminos reales, o que nuevamente se hagan, o que sólidamente se compongan" (Sarmiento: Apuntamientos ... sobre caminos reales..., Semanario Erudito, XX, 1789, § 35).
} 
afirmó Sánchez Agesta ${ }^{22}$. Pero lo cierto es que las alternativas más realistas emprendidas a partir de 1761 chocaron con la falta de fondos, por lo que tres décadas después prácticamente todos los caminos iniciados con Carlos III estaban a medio hacer, como señalaba Jovellanos en su Informe sobre la Ley Agraria.

Al ilustrado le duelen, como decía Sarrailh, algunas desalentadoras clases dirigentes anidadas en las ciudades: pelucas, golillas, corbatas, bonetes, capillas y espadas. Podemos sintetizar la crítica con palabras de Sarmiento: "entes efímeros (...) que para salir del día, en sus cuatro estaciones, por la mañana miran al sol que nace; a mediodía, atisban a mesa puesta, a la cual se pegan como parásitos. A la tarde, se entremeten, como piojo en costura, en los saraos, bailes y festejos. Y a la noche, se aparecen sin ser llamados en las casas de juego, para pedir barato, habiendo adulado a los que ganan"23.

El ilustrado se siente herido por las injusticias, y censura con frecuencia los abusos que se cometen con las gentes más humildes. Sarmiento repetía esta sentencia: "los malvados de raza abusan de cuatro cosas y se escudan con esa capa para imponer al pueblo. Estas son: Dios, Justicia, Rey y Bien Público" ${ }^{24}$. Y en su obra, como en la de otros de sus contemporáneos, podemos encontrar hoy ejemplos de la insolencia de todos aquellos que se escudaban con capa de justicias para extorsionar y abusar, en nombre de Dios, del Rey, de la Justicia y del Bien Público: curas, obispos, correligionarios, abades, alguaciles, corregidores, funcionarios...

El ilustrado se muestra abrumado con la crueldad de las leyes penales. Unos pocos atrevidos, como Feijoo, denuncian que "la tortura es medio sumamente falible en la inquisición de los delitos" 25 , ideas en las que más tarde insistieron otros, como Meléndez Valdés, Lardizábal o Jovellanos, aunque el tormento no sería abolido hasta las Cortes de Cádiz. Sarmiento fue, en este aspecto, uno de los más comprometidos, porque rechazó la pena de muerte al mismo tiempo que lo hacía el italiano Beccaria. Por eso me gusta repetir la definición que hizo de él Pilar Allegue: "home libre e bempensante, amante e practicante de la paz e dunha sociedade civil concibida e organizada con xustiza e solidaridade humana" 26 .

El ilustrado cree en la bondad del progreso. Realza, por ello, el valor de la ciencia y de la técnica, que entiende son atributos esenciales del progreso. Y en mayor o menor medida se interesa por conocer y difundir los avances científicos. Hay, naturalmente, muchos Teopompos que se oponen, como decía Feijoo:

"Es Teopompo uno de aquellos aristotélicos que se escandalizan, o muestran escandalizarse, aun de las voces sistema o fenómeno (...) ¿Pues qué si llega a saber que Leibnitz, Boyle y Newton fueron herejes? Aqui es donde prorrumpe en exclamaciones capaces de hacer temblar las pirámides egipcias. Aquí es donde se inflama el enojo, cubierto con la capa de celo. ¿Herejes? ¿Y éstos se citan? ¿O se hace memoria para cosa alguna de unos autores impíos, blasfemos, enemigos de Dios y de su Iglesia? ¡Oh, mal permitida libertad! ¡Oh, mal paliada envidia!, podría acaso exclamar yo. ;Oh, ignorancia abrigada de la hipocresía!’”27.

\footnotetext{
22 SÁnChez Agesta, L.: El pensamiento político del despotismo ilustrado, Madrid, 1953, pág. 135.

SARMIEnTo: Obra de 660 pliegos, Colección Dávila, XVII, 1ª , B.N., Ms. 20393, fol. 437.

SARMIEnTo: Obra de 660 pliegos, Colección Dávila, XVII, 1ª , B.N., Ms. 20393, fol. 347

Feijoo: Teatro Crítico, tomo 6, discurso primero, "Paradojas políticas y morales", paradoja 10.

Allegue, P.: A filosofía ilustrada de Fr. Martín Sarmiento, Vigo, 1993, pág. 39

FEıJoo: Cartas Eruditas, tomo 2, carta 16, "Causas del atraso que padece España en orden a las Ciencias Naturales, $\S 32-34$.
} 
El interés por la botánica propiciará la creación del Real Jardín Botánico de Madrid, la institución que se convertiría al poco tiempo en un prestigioso establecimiento científico de la Ilustración española, pues fue gracias a la botánica, desarrollada a partir de aquel centro, como se promovieron grandes relaciones científicas con Europa, haciendo de la botánica la principal aportación de los españoles a la ciencia ${ }^{28}$.

Prácticamente todos los ilustrados abogaron por reformar los planes de estudio de las Universidades para introducir materias utilitarias y prácticas que permitieran la renovación técnica y científica: matemáticas, botánica, física. La Universidad fue incapaz, sin embargo, de asumir aquel reto. Por eso se intentó encauzar la renovación mediante la fundación de otros centros e instituciones, como tertulias, academias, sociedades económicas, jardines botánicos, gabinetes, prensa $^{29}$.

Para el ilustrado el progreso significa mejora del pasado, y eso sólo puede hacerse cuando se conoce y se conserva el mayor número de huellas de otros tiempos. Es por eso que, casi sin quererlo, se convierte en anticuario, en coleccionista y aficionado a la historia. Y digo aficionado para no confundir los términos, porque como decía Feijoo, "la verdad navega en el mar de la historia siempre entre dos escollos: la ignorancia y la pasión. En lo que no toca al historiador muy de cerca, suele faltarle la noticia: en lo que le pertenece y mira como suyo, habla contra la noticia el afecto" ${ }^{30}$. El historiador ilustrado es el que adopta una metodología crítica, en sintonía con los benedictinos de San Mauro, rechazando contundentemente las falsificaciones históricas y basando sus análisis en las fuentes documentales originales, que se esfuerza en recuperar y publicar.

"Dos cosas -decía Mayans en el Prefacio de las Obras Chronológicas del Marqués de Mondéjar- entiendo yo que son necesarias para la perfección de la Historia de España; es a saber, la enmienda de las memorias impresas y la publicación de muchas no divulgadas"31. Y fueron muchos los ilustrados que se dedicaron a reunir colecciones documentales, entre las que hay que destacar sin duda la España Sagrada de Flórez y Risco, obra que en muchos aspectos todavía es válida en nuestros días, aunque debamos tener en cuenta la crítica planteada ya en su día por Mayans en cuanto a la complacencia de Flórez con respecto a algunas tradiciones eclesiásticas, como la venida de Santiago y la Virgen del Pilar.

El ilustrado, convencido de la perfectibilidad del ser humano y de la sociedad, se interesó especialmente por fomentar y proteger la cultura. Tanto fue así que Jean Sarrailh creyó ver en la actividad cultural de nuestros ilustrados un ídolo místico de progreso -la culture utilitaire et dirigée - sustitutivo de la Raison philosophique. Se puede discutir, como luego haré con más detalle, algunas conclusiones precipitadas derivadas de esa idea, como que las luces españolas carecieron por completo de elementos utópicos y sólo estuvieron guiadas y encauzadas por referentes utilitarios y pragmáticos provenientes de las esferas del poder. Pero hay que aceptar que el reformismo cultural y económico es una característica substancial de la ilustración española.

No gastaré mucha tinta en afirmar que Sarmiento fue uno de los principales impulsores de las reformas culturales emprendidas durante el reinado de Fernando VI. Bastará con recordar que es de mi total responsabilidad el subtítulo que figura en la edición moderna de sus Reflexiones

28 Puerto Sarmiento, F. J.: La ilusión quebrada. Botánica, sanidad y política científica. Madrid, 1988.

29 Escolano, A.: Educación y economía en la España Ilustrada, Madrid, 1988. Acerca de la educación y la prensa puede verse Labrador, C. y De Pablos, J.C.: La educación en los papeles periódicos de la Ilustración española, Madrid, MEC, 1989.

30 Feijoo: Teatro Crítico, Tomo 4, discurso 8, "Reflexiones sobre la Historia", §. X, 25

31 Mayans: Obras completas, vol. I, Oliva, Ayuntamiento, 1983, págs. 429 y ss. Las obras de Mayans son asequibles en internet en la Biblioteca Valenciana Digital, http://bv2.gva.es 
Literarias para una Biblioteca Real ${ }^{32}$. Allí afirmo, e intento justificar, que las reformas culturales de la Ilustración española, tal y como se entendieron a partir del reinado de Fernando VI, tienen su origen en el plan sistemático, organizado y coherente de Sarmiento. Coincide en muchos aspectos con los Pensamientos Literarios que Mayans dirigió a Patiño en 1734, pero fue la propuesta del benedictino la que tomaron Rávago y los asesores de Ensenada; y más tarde Campomanes.

$\mathrm{Al}$ ilustrado le duele la miseria cultural, la ignorancia y la superstición generalizadas, porque con ellas es fácil manipular a la masa crédula. Es por eso que piensa en que además de mejorar las condiciones materiales y económicas hay que reformar la miserable enseñanza basada en el memorismo y en los castigos corporales; y que es necesario formar también a los maestros, tan o más ignorantes, necios y crédulos que el pueblo analfabeto. Por eso dijo bien Ángeles Galino que Feijoo, Sarmiento y Jovellanos constituyen tres respuestas a un mismo problema, el de la educación moderna ${ }^{33}$.

Todo eso, al menos, hay que tener en cuenta antes de proponer el carácter ilustrado de tal o cual personaje. Porque los hay que hoy pasan por ilustrados habiendo cerrado los ojos ante la injusticia, el abuso, la miseria y la ignorancia; y sin haberse interesado por la historia, la ciencia, la educación o la cultura. Verdad es que muchos ilustrados ejercieron actividades políticas, pero no es la política lo que permite definir al ilustrado, sino su actividad intelectual, si se me permite el uso de ese vocablo anacrónico.

Quiero decir que no puede proponerse como ilustrado a tal o cual personaje del siglo XVIII por el mero hecho de haber sido político. El ilustrado es lo que hoy llamaríamos un intelectual, preocupado por mejorar los estudios, la creación literaria, científica o artística, proponiendo para ello medidas de reforma, redactando proyectos, emitiendo informes... Por eso es un ilustrado Campomanes, a pesar de sus contradicciones y de que no siempre ajustó las ideas y teorías a sus prácticas. Pero no puede considerarse como ilustrados al Marqués de la Ensenada o al Conde de Aranda, como se ha hecho con frecuencia. Habrán sido mejores o peores estadistas y políticos, pero no ilustrados.

En ese mismo sentido, creo que es una ambigüedad y un paracronismo el uso de la expresión despotismo ilustrado, por más que se haya generalizado y ya constituya una categoría histórica. Verdad es que la mayoría de los ilustrados españoles no cuestionaron la monarquía como forma de gobierno, y verdad es también que hubo un tiempo en que las aspiraciones y las iniciativas de los ilustrados y de los déspotas vinieron a coincidir. Pero mientras el déspota se aferra, como sea, a sus ideas de dominio y de control, el pensamiento ilustrado evoluciona, que es otra manera de expresar lo que dijo Julián Marías: "lo malo es que la ilustración pasa y el despotismo queda, y los pueblos de Europa lo experimentaron en sus propias carnes"34.

Que ilustrado y déspota son conceptos excluyentes lo señaló con acierto François Lopez ${ }^{35}$; y por si no quedara claro, convendría leer lo que Jovellanos escribió en su Diario el jueves 6 de agosto de 1795, con ocasión de la negativa del Cardenal Lorenzana, a la sazón inquisidor General, para permitir que el Real Instituto Asturiano contase en su biblioteca con libros de física y mineralogía que figuraban en el Índice:

\footnotetext{
32 Sarmiento: Reflexiones Literarias para una Biblioteca Real, edición, y estudio de J. Santos, Santiago, Consello da Cultura Galega, 2002. El trabajo puede obtenerse en internet, http://www.consellodacultura.org/mediateca/pub.pdf/reflexions.pdf Galino, M.A.: Feijoo, Sarmiento y Jovellanos, tres hombres y un problema ante la educación moderna, Madrid, CSIC, 1953. Marías, J.: La España posible en tiempo de Carlos III, Barcelona, Planeta, 1988, pág. 23

Lopez, F.: "Rasgos peculiares de la Ilustración en España”, en Mayans y la Ilustración, Valencia, Universidad, 1981.
} 
“Este monumento de barbarie debe quedar unido al Diario. ¿Qué dirá de él la generación que nos aguarda, y que, a pesar del despotismo y la ignorancia que la oprimen, será más ilustrada, más libre y feliz que la presente? ¿Qué barreras podrán cerrar las avenidas de la luz y la ilustración?’36.

Y creo que tampoco tiene mucho sentido hablar de una Ilustración cristiana. Cierto es que ya Paul Hazard, ante las supuestas dificultades para encuadrar en el movimiento liberador de las luces a la mayoría de los ilustrados italianos, alemanes y españoles planteó la existencia de una "novedad que no se ha inscrito aún en la historia", la de una ilustración cristiana, que en la versión castellana el autor analizaba en un capítulo denominado la Apologética de la religión ${ }^{37 .}$

Esa idea cobró gran fuerza para intentar explicar los nexos entre el movimiento de las luces alemanas, italianas, portuguesas o españolas. En lo que concierne al caso de España, después del trabajo pionero de Rodríguez Casado, han sido numerosos los intentos de caracterizar a ese pretendida ilustración cristiana, entre los que cabe destacar a Mestre en torno a las ideas religiosas de Mayans, a Saugnieux acerca de Tavira ${ }^{38}$.

A mi me parece que se trata de intentar hacer compatible lo que es antagónico y de conciliar lo que es irreconciliable como dijo Aguilar Piñal ${ }^{39}$. Y puede incluso considerarse improbable y gratuito para el caso de España, como afirma Francisco Sánchez-Blanco ${ }^{40}$. La mayoría de nuestros ilustrados eran cristianos, pero no son sus convicciones religiosas las que nos permiten analizar sus ideas ilustradas. Si hoy podemos decir que Feijoo, Jovellanos, Campomanes, Mayans, Sarmiento y tantos otros, formaron parte del movimiento de las luces, y por eso podemos analizar sus ideas desde esa perspectiva, es porque a la hora de exponer, valorar y difundir sus ideas se despojaron de los dogmatismos. La mayoría de ellos no abandonaron sus prácticas religiosas y continuaron siendo dogmáticos en cuestiones de teología, pero supieron desligar los dogmas y la religión de la ciencia, de la naturaleza, de la explicación histórica y lingüística e incluso de sus actividades culturales, públicas y políticas, sin que su cristianismo sufriera la menor merma.

\section{LA ILUSTRACIÓN DE LA UTOPÍA}

Para los estudios sobre Martín Sarmiento fue también muy importante el año de 1972, ya que entonces se cumplía el segundo centenario de su muerte y con ese motivo se encargó al profesor José Luis Pensado el Discurso de Apertura del curso académico de la Universidad de Salamanca, que naturalmente centró en la figura del benedictino ${ }^{41}$. Por esas mismas fechas apareció en Oviedo una obra de Manuel Lanz de Casafonda, Diálogos de Chindulza, escrita alrededor de 1762 y que ahora la sacaba a la luz Francisco Aguilar Piñal, que ya era un reconocido especialista del siglo XVIII, como prueban algunas de las obras que tenía publicadas: La Sevilla de Olavide, 1966; La Real Academia Sevillana de Buenas Letras en el siglo XVIII, 1966; Los comienzos de la crisis universitaria en España, 1967; La Universidad de Sevilla en el siglo XVIII, 1969.

\footnotetext{
Jovellanos: Diarios, cito por la edición de J.M. Caso, pág. 277.

Hazard, P.: El pensamiento europeo en el siglo XVIII, Madrid, Alianza, 1985, cap. VI

Rodríguez Casado, V.: "El intento español de una ilustración cristiana", Estudios Americanos, 42, (1955), 141-169; Mestre, A.: Ilustración y reforma de la Iglesia. Pensamiento político-religioso de Don Gregorio Mayans i Siscar, Valencia, 1968; Saugnieux, J.: La ilustración cristiana española. Escritos de Antonio Tavira, Salamanca, 1986.

Aguilar Piñal, F. (ed.): Historia literaria de España en el siglo XVIII, Madrid, 1996, pág. 34.

Sánchez-Blanco, F.: El Absolutismo de las Luces en el reinado de Carlos III, Madrid, Marcial Pons, 2002, pág.11.

Pensado, J. L.: Fray Martín Sarmiento, testigo de su siglo, Salamanca, Universidad, 1972.
} 
El autor de los Diálogos de Chindulza, en fingida conversación entre dos abates italianos, Sabelli y Bartoli, venía a alabar la cultura española de la Ilustración, a la vez que ridiculizaba los métodos escolásticos de la enseñanza universitaria y abogaba por la reforma de los colegios mayores. En un determinado momento Sabelli pedía a su contertulio que le diera cuenta de los literatos que había conocido en Madrid. Y Bartoli señalaba:

"El más sabio de los literatos que traté en Madrid fue un monje benito, y es aquel de quien habla el Muratori al nuncio Henrique en la dedicatoria del segundo tomo de sus Misiones del Paraguay. Este monje es de aquellos que al principio te conté que no se aplicaban tanto al estudio de la ciencia que profesan cuanto a otras muy ajenas a su profesión y estado. No hay duda que su erudición es vasta, pero por un rumbo muy extraño se ha dado a un género de literatura a que pocos se dedican, y esto ha hecho que tenga más crédito del que en la realidad merece. Su fuente son las antigüedades, y sabe mucho de disciplina militar y triunfos de los romanos, de sus armas, escudos, sellos, vestiduras, calzadas, convites, baños, juegos, granjas, edificios, acueductos y cloacas, ferias y ceremonias, fiestas de su falsa religión, votos, sacrificios, oráculos, inscripciones sepulcrales, y otras cosas de este jaez, especialmente las que tocan a asuntos raros y extravagantes, sobre que ha hecho algunas disertaciones. Una estaba trabajando cuando yo sali de Madrid sobre el origen de la enfermedad de las bubas, y otra compuso el año pasado sobre un sátiro que unos alemanes trajeron a enseñar a España, y es tal su propensión a este género de estudios que sería muy repugnante a su genio el haber de escribir en otras materias" ${ }^{2}$.

Sorprende la nota al pie de página del editor Aguilar Piñal: "se trata del P. Feijoo, como se comprueba en el curso de esta conversación. No obstante, en la citada dedicatoria, Muratori habla del P. Sarmiento". Y sorprende al menos por dos razones. La primera, porque Aguilar Piñal fechaba el escrito de Lanz de Casafonda en el otoño de 1761, pero Feijoo no escribía en Madrid, ni estuvo en la Corte en esas fechas, ya que permanecía en Oviedo, lejos de la Ingrata habitación de la Corte que tanto le incomodaba.

Y segunda, porque todos los indicios y datos que aportaba Lanz de Casafonda, en boca de Bartoli, apuntan hacia Martín Sarmiento y no hacia Feijoo. Sarmiento era, efectivamente, el que Muratori alababa en la dedicatoria citada. Y el mismo Sarmiento era quien, pertrechado en su celda del monasterio de San Martín de Madrid, había escrito a finales de septiembre de 1760 diez pliegos Sobre el papion o cynocephalo, y el 18 de julio de 1761 gastaba otros 34 pliegos para tratar Sobre el origen de las bubas ${ }^{43}$.

Que Lanz de Casafonda elogió y criticó la obra de Sarmiento ya lo expuso Sempere y Guarinos, en su Ensayo de una Biblioteca Española, voz "Casafonda". Allí, cuando trata de esa obra manuscrita, que Sempere titula Del estado presente de la Literatura Española (...) Diálogo entre dos Abates Napolitanos, señala que en ella ".se hace una pintura fiel de los principales literatos, particularmente del Señor Bayer, los Padres Flórez, Burriel, Sarmiento, Feijoo, D. Luis José de Velázquez, D. Gregorio Mayans, y Don Agustín Montiano, formando el debido elogio de sus obras, pero sin ocultar sus defectos" $"$.

No quisiera que concluyeran de estas referencias una crítica negativa para con Aguilar Piñal, pues, como la mayoría de los lectores seguramente saben, no sólo es uno de nuestros más importantes especialistas del siglo XVIII, sino que también es quien mejor conoce en España la

42 Lanz de Casafonda, M.: Diálogos de Chindulza, edición de F. Aguilar Piñal, Oviedo, Cátedra Feijoo, 1972 , pág. 38.

43 El primero permanece inédito. Del segundo hay edición, incompleta y defectuosa, Antigüedad de las bubas, extracto, Madrid, imprenta de Blas Román, 1787.

44 Sempere y Guarinos, J.: Ensayo de una biblioteca española de los mejores escritores del reinado de Carlos III, Madrid, Imprenta Real, 1785, tomo 2. 
bibliografía ilustrada. Ahí está su monumental Bibliografía de autores españoles del siglo XVIII para probarlo. Lo que quiero significar es cómo Sarmiento puede fácilmente pasar desapercibido para quienes no se dedican expresamente a su estudio, aún cuando sean reconocidos especialistas del siglo XVIII, y precisamente en un año tan importante para su bio-bibliografía, como lo fue el de 1972.

Las citas y referencias de los escritos de Sarmiento, que Lanz de Casafonda pone en boca de Bartoli, nos señalan las estrechas relaciones que el autor tenía con el benedictino Sarmiento, ya que aquellos escritos, recién finalizados, sólo eran conocidos por sus amigos y allegados. Y casi todos, al igual que Casafonda, se quejaban de que sólo se dedicase a lo que ellos entendían como cuestiones raras y extravagantes y no orientase sus esfuerzos intelectuales a ser más útil al público, escribiendo sobre las cuestiones que desde los últimos años de Fernando VI y después con Carlos III eran precisas para orientar las políticas de reforma agraria, comercial y de obras públicas.

Ninguno entendió sus motivaciones ni la importancia de lo que entonces salía de la pluma de Sarmiento. En ese sentido, una carta escrita a su amigo Medinasidonia nos aclara por qué se decidió a escribir sobre el animal papión: "tengo ya evidencia de que aquel animal, que cuatro impostores están embocando a los de Madrid que es un sátiro, un hombre silvestre, y, si se les antoja, que es un ángel salvaje, es un mono, monazo (...) Su verdadero nombre es Papio" ${ }^{45}$. Lo extravagante no era que Sarmiento escribiese 10 pliegos para mostrar qué animal era el papión, lo raro y extravagante era que los madrileños que llamaban extravagante al benedictino, pagasen una peseta para admirar como hombre silvestre y sátiro a un mono monazo. Y eso derivaba de la poca importancia que se daba a la historia natural. Por eso Sarmiento era raro, aunque a él le importaba poco: "Si los demás españoles desprecian o censuran la historia natural, para ser únicos en Europa, yo no quiero ser de esos españoles, ni tan ignorante como ellos"46.

Tampoco era raro ni extravagante su escrito Sobre el origen y antigüedad de las bubas, en el que venía a mostrar que esa enfermedad no provenía de América, como era común afirmar en aquel tiempo, sino que ya existía en España y en Italia antes del descubrimiento de América, como probaba con una cita de Pedro Mártir de Anglería, que evidenciaba que el primero que pudiera considerarse portador de la enfermedad era el catedrático de Salamanca, Arias Barbosa.

Y como la mayoría de los lectores no tendrán ocasión de enfrentarse con aquella obra Sobre las bubas, que se publicó en 1787 en una edición incompleta y defectuosa, viene bien seguir su consejo: "El lector que no tuviere ocasión de leer mis 34 pliegos sobre la historia de las bubas, conténtese aquí con saber el origen del error común. Gonzalo Fernández de Oviedo era paje del Rey Católico. Pasó con él a Nápoles hacia el año de 1505, advirtió que ya allí reinaban las bubas, y creyó que las habían traído de la América los compañeros de Colón. Hacia los años de 1515 pasó a la América y a la Isla de Santo Domingo. Y como allí vio que reinaban las bubas, se ratificó en su primer error, y dio por hecho en su Crónica, que las bubas habían venido de la América. A Oviedo siguieron, como carneros, casi todos los que escribieron después de él" ${ }^{\prime 7}$.

Hay una actividad intelectual de Sarmiento que fue precursora y por la que merece figurar entre los grandes europeos de su tiempo: sus estudios lingüísticos. Porque fue el pionero y el más avanzado filólogo románico de su tiempo, como en parte señaló Lázaro Carreter y como

\footnotetext{
Sarmiento: Cartas al Duque de Medinasidonia, citada, Carta 19 de agosto de 1760.

Sarmiento: Cartas al Duque de Medinasidonia, citada, Carta de 6 de Agosto de 1760

Sarmiento: Obra de 660 pliegos, Colección Dávila, XVII, 1ª, B.N., Ms. 20393, fol. 469
} 
ha mostrado después en numerosos trabajos el profesor José Luis Pensado ${ }^{48}$. Si hoy no tiene un sitio entre los europeos de la ilustración es porque al negarse a dar a luz sus escritos, sus ideas lingüísticas no influyeron en Europa y hubo que esperar a que otros reinventaran esas mismas ideas algunas décadas después.

Otra faceta pionera fue su dedicación intelectual al estudio y recogida de las manifestaciones lingüísticas, folklóricas y culturales del pueblo; es decir, a la investigación de saberes con vitalidad, centrados en la legitimidad de la cultura popular, al tiempo que en las Academias, en los salones y en las tertulias se empezaron a encerrar los saberes oficiales. Si por esa actividad no pasó a la posterioridad europea es porque en tiempos de uniformidad lingüística y castellanización él se interesó por la lengua, la cultura y el folklore del pueblo gallego, reclamando la lengua vernácula en la enseñanza. Y a veces lo expresó de forma tan contundente que aún hoy sus palabras levantarían ampollas:

“¿Quién de los dos se debe acomodar a una lengua sola, el niño a la que, fuera de la provincial, ha mamado el maestro, o éste a la que el mismo niño ha mamado? Luego, el maestro que fuere incapaz de acomodarse así, como lo dicta la razón natural que se acomode, debe volverse a su tierra, si es extraño; y si es compatriota, debe estudiar primero la lengua nativa, antes de entremeterse a ser maestro" 49 .

Puede decirse por eso que Sarmiento asumió, a la vez, dos compromisos: uno en el ámbito lingüístico -científico, educativo y de corte ilustrado-, con el estudio de la lengua gallega; y otro político y nacionalista, cuando el nacionalismo aún no había aparecido en la historia, centrado en la recuperación, la dignificación y la enseñanza de su lengua y de su cultura popular ${ }^{50}$. Es por esta última precursoría por la que en buena medida las Letras Gallegas le rindieron tributo y reconocimiento el año 2002.

Sin embargo ésta ya no es una manifestación ilustrada, y por eso sus propuestas a contracorriente fueron consideradas ridículas y disparatadas; incluso entre los propios gallegos. Sarmiento era consciente de ello; es decir, sabía que si la centralización y la castellanización constituían el éxito de la política ilustrada, sus ideas acerca de la lengua habían de entenderse como fracaso. Ese fue su gran fracaso: adelantarse a su tiempo, y mantener su independencia de criterios sabiendo que nadie le había de entender. Aunque a él le importaba poco, como le decía a su amigo Campomanes:

"Recibí la de VS al tiempo que estaba dando una tunda a mi Glosario burlesco gallego-latino. Digo burlesco, pues sé que los más que se habrán de burlar de él y de mí habrán de ser los gallegos. La razón es palmaria. Los gallegos son tenaces en conservar sus vejeces. No hay cosa, o hay pocas, en el Glosario que no les pareciese nueva. Novedades fuera, dirán. La lengua gallega es aborigene, y ab origine mundi (...) ¿En dónde estamos? dirían otros que no son de Galicia (...) ¿Con qué conciencia se viene el fraile a escribir seriamente de una lengua que no hay y que es delito hablar de ella? Bien se conoce que el chorrillo de escribir es invención de frailes. Que escriban en

48 Lázaro Carreter, F.: Las ideas lingüísticas en España durante el siglo XVIII, Madrid, 1949; Pensado, J.L.: Fray Martín Sarmiento, sus ideas lingüísticas, Oviedo, 1960.

49 Sarmiento: Obra de 660 pliegos, Dávila, § 5312. Además del ya citado texto de Ángeles Galino acerca de sus ideas sobre la educación puede verse también Dahlmann, L. M.: "El discurso pedagógico en la obra de Fr. Martín Sarmiento", Trocadero, 10-11 (1999), 7-48; Santos Puerto, J.: Martín Sarmiento: Ilustración, Educación y Utopía en la España del siglo XVIII, A Coruña, Fundación Barrié de la Maza, 2002, vol. 2. Y Fr. M. Sarmiento: La Educación de la niñez y de la juventud, edición de A. Costa y M. Álvarez, Madrid, Biblioteca Nueva, 2002.

50 Acerca de Sarmiento y la lengua gallega remito al estudio de Monteagudo, H.: Sobre a Lingua Galega. Fr. Martín Sarmiento. Antología, Vigo, Galaxia, 2002. 
castellano, vaya. Que escriban en latín, venga. Que traduzcan del francés (...) pase. Pero querer hacer análisis de las voces gallegas y de las cosas que significan, teniendo atrevimiento para citar los autores más clásicos (...) es, no ya invención de frailes, sino de algún fraile de invenciones (...) Amigo, parece que estoy oyendo a gallegos y castellanos que me dicen estas lisonjas. Pero yo proseguiré con mi tema del Glosario y Onomástico hasta que me canse ${ }{ }_{51}$.

Cotejando la Real Cédula de Instrucción y Fuero de Población de Sierra Morena con la obra de Sarmiento, he mostrado que muchas de las ideas que aparecen en la Instrucción y Fuero son deudoras de la boca y de la pluma del benedictino; y que, además, algunas fueron tomadas de sus escritos al pie de la letra ${ }^{52}$. De manera que a él habrá también que asignarle un lugar relevante en la planificación de la utopía colonizadora ilustrada, en esa utopía que Caro Baroja llamó experimento sociológico en tiempos de Carlos III, y que hasta ahora se atribuía sólo a Campomanes y Olavide.

También he dedicado algunas páginas a explorar la posibilidad de atribuir a nuestro benedictino la autoría de La Sinapia $^{53}$. Aunque las pruebas aportadas no son definitivas, presento argumentos e indicios suficientes para valorar esa posibilidad, complementando las propuestas de otros autores ${ }^{54}$. De todas maneras creo que lo substancial no es saber si Sarmiento fue o no el creador de La Sinapia, que eso sólo servirá para completar una referencia literaria y bibliográfica. Lo importante, creo yo, es saber que Sarmiento es el creador de una Gran Sinapia, que está contenida en sus líneas principales en sus Notas al Privilegio de Ordoño y en su Obra de 660 pliegos, que todavía permanecen inéditas. Lo importante es saber que Sarmiento, un hombre a todas luces ilustrado y representante destacado de la ilustración española en la primera mitad del siglo XVIII, puede ser también considerado el principal representante de la utopía española del siglo de las luces.

Sarmiento comenzó a evolucionar hacia la utopía y a pasarse al otro bando cuando tomó contacto con la realidad de su tierra gallega en el viaje que hizo en 1745. A partir de entonces comienza a reivindicar la cultura popular de los hombres y mujeres de su tierra gallega, de quienes tanto acaba de aprender. Los compromisos que tiene que asumir en Madrid, en relación con los adornos del Palacio Real, dejan en suspenso la evolución, que se convierte en revoltura una década después, tras el viaje a Galicia en 1754-55. Es entonces cuando advierte con claridad la desgracia y la miseria de un pueblo sojuzgado y humillado, pero que conserva el espíritu de su renacer futuro: su lengua, su tradición y su cultura. La utopía era la lógica evolución a la que se veía abocado aquel hombre otrora ilustrado porque no tenía intereses personales para seguir la senda del déspota de turno; y porque a la fortuna antepuso los intereses de su pueblo, a sabiendas de que sería despreciado por sus amigos y contemporáneos.

Sarmiento se dio cuenta, evidentemente, de que su pensamiento había traspasado los límites de la Ilustración. Sabía que ya poco tenía que ver con aquel joven que defendiera en otro tiempo a Feijoo, porque sus ideas ya no concordaban con las de su maestro ni con las que él mismo había mantenido décadas antes. Y sabía también que Feijoo aún era la referencia de la philosophie española de la primera mitad del siglo, y que a él se le consideraba representante oficioso de Feijoo en Madrid. Por eso no podía ni quería polemizar ni romper públicamente

51 Díaz, S.: "El P. Sarmiento en los archivos de Campomanes y Silos: seis cartas más", Cuadernos de Estudios Gallegos, XXVII (1972) pp. 312-314. Carta a Campomanes, de 19/9/1761.

52 Santos Puerto, J.: Martín Sarmiento: Ilustración, Educación y Utopía ..., citada, vol. 2, cap. IX, epígrafe 3, "Otra utopía: influencia en la planificación para repoblar Sierra Morena".

53 Santos Puerto, J.: "La Sinapia: Luces para buscar la utopía de la Ilustración”, Bulletin Hispanique, nº 2, diciembre 2001, 481-510.

54 Cro, S.: Descripción de la Sinapia, península en la tierra austral. A Classical Utopia of Spain 
con quienes se declaraban devotos discípulos. Ese fue el drama del hombre más independiente de su siglo.

También se dieron cuenta del cambio sus amigos. Algunos consideraron que su fuga era una excentricidad e intentaron convencerle de que escribiese y publicase trabajos útiles al Público. Sin conseguirlo, como se quejaba Lanz de Casafonda. Otros sabían que las investigaciones emprendidas tras su vuelta de Galicia eran una brecha abierta que cerraba la puerta a lo que ellos entendían como progreso. Y como él no consentía en dejar enguantar sus luces y sus sombras, comenzó a ser despreciado, desprestigiado y arrinconado por hombres de mediocres luces, muchos de los cuales hoy se catalogan, con escasos argumentos, como ilustrados. Por eso, fundamentalmente, Sarmiento nos resulta hoy casi desconocido fuera de Galicia y de la historia de la educación.

Fue el silencio y la censura (en su caso autocensura) contra la ilustración utópica española la que le comenzó a olvidar y a despreciar, ya en su tiempo. Y después, casi en nuestros días, cuando fue reinventada la Ilustración pragmática y funcionarial, esa de la que habló Jean Sarrailh sin citarle, también quedó relegado porque sus ideas e investigaciones no casan con el concepto de la culture utilitaire, culture dirigée, que tanto ha contribuido a desorientar en las últimas décadas algunas investigaciones sobre nuestra ilustración. Y las nuevas ideologías bienpensantes acaso no pueden sustraerse de las sendas marcadas y de los caminos ya desbrozados, como decía el profesor Caso. 